\title{
FLORESCIMENTO E PRODUÇÃO DE MARACUJAZEIRO-AMARELO OBTIDO POR ENXERTIA HIPOCOTILEDONAR EM JABOTICABAL-SP E ARAGUARI-MG ${ }^{1}$
}

\author{
GERALDO COSTA NOGUEIRA FILHO ${ }^{2}$, GIVANILDO RONCATTO ${ }^{3}$, CARLOS RUGGIERO ${ }^{4}$, \\ JOÃO CARLOS DE OLIVEIRA ${ }^{4}$, EUCLIDES BRAGA MALHEIROS ${ }^{4}$
}

RESUMO - O trabalho foi realizado no ripado e na área de Fruticultura do Departamento de Produção Vegetal da Faculdade de Ciências Agrárias e Veterinárias, Universidade Estadual Paulista (FCAV/UNESP), em Jaboticabal-SP, e em área de pequeno produtor fornecedor da Maguari (Kraft Foods do Brasil), em Araguari-MG, tendo por objetivo avaliar o desenvolvimento de maracujazeiro-amarelo enxertado por enxertia hipocotiledonar, sobre seis espécies de Passifloraceas. Foram utilizados sete tratamentos, sendo seis tratamentos com as espécies: $P$. edulis f. flavicarpa, P. caerulea, P. alata, P. gibertii, P. coccinea, P. cincinnata e um tratamento com pé-franco de $P$. edulis f. flavicarpa. Para todos os tratamentos, a variedade-copa utilizada foi o maracujazeiro-amarelo 'FB 200'. O delineamento experimental utilizado foi o de blocos ao acaso, com três repetições. A parcela foi constituída de uma linha de quatro plantas (20m lineares). A condução foi realizada conforme os tratos culturais recomendados para a cultura. As características avaliadas foram florescimento, produção, número e peso médio de frutos. Em Jaboticabal-SP, o pé-franco apresentou melhor desenvolvimento e maior produção que as plantas enxertadas. Em Araguari-MG, P. edulis f. flavicarpa, $P$. caerulea e pé-franco apresentaram melhor produção. Não houve diferença significativa no número de frutos, e o P. alata diminuiu, em relação aos outros porta-enxertos, o peso dos frutos.

Termos para indexação: Passiflora spp., propagação vegetativa, desempenho agronômico.

\section{FLOWERING AND PRODUCTION OF YELLOW PASSION FRUIT OBTAINED BY HYPOCOTYLEDONARY GRAFTED IN JABOTICABAL AND ARAGUARI}

\begin{abstract}
The study was conducted in the ripped area, and in the Fruitculture area of the Department of Plant Production, Faculdade de Ciências Agrárias e Veterinárias, Universidade Estadual Paulista (FCAV/ UNESP), in Jaboticabal (Sao Paulo, Brazil), and in an area of a small producer supplier of Maguari (Kraft Foods of Brazil) in Araguari (Minas Gerais, Brazil), and aimed to assess the development of yellow passion fruit grafted by hypocotyledonary grafting, on six rootstocks of Passifloraceas. Seven treatments were used, with six treatments and rootstocks: $P$. edulis f. flavicarpa, P. caerulea, P. alata, P. gibertii, P. coccinea, P. cincinnata and treatment with non-grafted plants of the $P$. edulis f. flavicarpa. For all treatments the crown variety used was the yellow passion fruit plant 'FB 200'. The experimental design used was randomized blocks with three repetitions. The plot was formed in a line of four plants (20 linear meters). The conduction was done according to cultural treatments recommended for this culture. The evaluated characteristics were flowering, production, number and average fruit weight. In Jaboticabal the seedling plants presented the better development and higher production than the others. In Araguari P. edulis f. flavicarpa, P. caerulea, and seedling plants presented the better production. No differences between rootstocks were found to fruit number and P. alata decreased the fruit weight compared to the other rootstocks.
\end{abstract}

Index terms: Passiflora spp.; vegetative propagation; agronomic performance.

\footnotetext{
1.(Trabalho 019-10). Recebido em: 05-01-2010. Aceito para publicação em: 16-10-2010.

${ }^{2}$ In memorian.

${ }^{3}$ Pesquisador A da Embrapa Mato Grosso. Avenida das Itaúbas, 3257 - Setor Comercial, Cep 78550-194, Sinop - MT.

${ }^{4}$ Professor Titular da Unesp/Fcav. Via de acesso Paulo Donato Castellane, s/n Cep 14884-900 Jaboticabal-SP. E-mails: ruggiero@fcav.unesp.br; jocaoliv@fcav.unesp.br; euclides@fcav.unesp.br
} 


\section{INTRODUÇÃO}

O Brasil é o maior produtor mundial de maracujá (Passiflora spp.). Em 2008, apresentou uma produção de 684 mil toneladas, com área de aproximadamente 49 mil hectares, destacando-se o Estado da Bahia como o principal produtor, com 275 mil toneladas, em 20 mil hectares. Em seguida, Ceará, com 112 mil, em 5 mil hectares; Espírito Santo, com 66 mil toneladas, em 2,5 mil hectares; Sergipe, com 44 mil toneladas, em 4,5 mil hectares, e Minas Gerais, com 38 mil toneladas, em 2,6 mil hectares (IBGE, 2009).

A região de Marília - SP, tem-se caracterizado como a principal região produtora no Estado, com produção de frutos destinados ao consumo de fruta fresca. Já a região de Araguari - MG (2.800 ha), tem possibilitado o cultivo desde 1971, há mais de 30 anos, praticamente nas mesmas áreas, voltado principalmente para atender à indústria de suco (SILVA et al., 2005).

O maracujazeiro-amarelo, normalmente propagado por via sexuada, tem apresentado uma redução da longevidade de seus pomares, principalmente devido aos problemas fitossanitários que atingem o sistema radicular e a parte aérea (SILVA et al., 2005).

A pesquisa vem buscando fontes de resistência como solução a esses problemas fitossanitários entre outras espécies de Passifloráceas. Essas seriam usadas possivelmente em programas de melhoramento, tentando-se transferir a característica de resistência ao maracujazeiro-amarelo, ou de forma mais fácil e imediata como porta-enxertos (JUNQUEIRA at al., 2006).

Alguns profissionais que trabalham com essa cultura têm apontado o uso da enxertia como forma de resolver esses problemas, baseados em experiência semelhante em outros países e ainda em problemas similares com outras culturas, como a gomose em citros e a filoxera na uva europeia (Vitis vinifera) (CHAVES et al., 2004).

Dessa forma, tem-se procurado estudar aspectos relativos à produção de mudas enxertadas, compatibilidade entre enxerto e porta-enxerto, e, em alguns casos, a sobrevivência dessas mudas no campo. Mas ainda é pequeno o número de espécies testadas e mesmo acerca daquelas sobre as quais tem sido feito algum estudo, fazendo-se necessário aprofundar os mesmos, inclusive envolvendo a fase de produção propriamente dita e as relações portaenxerto/copa, que podem intervir na qualidade do fruto e/ou suco. Além de avaliar-se outras espécies ainda não testadas como porta-enxerto.

Por isso, constituiu-se como objetivo deste trabalho a avaliação do florescimento e da produção de seis espécies nativas de passifloras como porta-enxerto para o maracujazeiro-amarelo, em Jaboticabal-SP, e em Araguari-MG.

\section{MATERIAL E MÉTODOS}

O experimento foi realizado no ripado e na área de fruticultura do Departamento de Produção Vegetal da Faculdade de Ciências Agrárias e Veterinárias de Jaboticabal-SP (FCAV), Universidade Estadual Paulista (UNESP), localizada a $610 \mathrm{~m}$ de altitude, $21^{\circ} 15^{\prime} 17^{\prime \prime} \mathrm{S}$ de latitude e $48^{\circ} 19^{\prime} 20^{\prime \prime} \mathrm{W}$ de longitude, e em área de pequeno produtor, em Araguari-MG, no período de abril de 2002 a março de 2003. De acordo com a classificação de Köeppen, o clima é do tipo Cwa, isto é, subtropical temperado, seco no inverno, com temperatura do mês mais quente superior a $22^{\circ} \mathrm{C}$. A precipitação média anual e a temperatura oscilam em torno de $1.400 \mathrm{~mm}$ e $22^{\circ} \mathrm{C}$, respectivamente. Em Araguari-MG, as coordenadas são $18^{\circ} 38^{\prime} 30^{\prime \prime} \mathrm{S}$ e $48^{\circ} 11^{\prime} 18^{\prime \prime} \mathrm{W}$, e a altitude média de 900 m. De acordo com a classificação de Köeppen, o clima é do tipo Cwb, tropical quente e úmido, seco no inverno, temperatura média de $20,7^{\circ} \mathrm{C}$, com máxima de $24,2^{\circ} \mathrm{C}$ e mínima de $20^{\circ} \mathrm{C}$, precipitação média anual de $1.484 \mathrm{~mm}$.

Foram realizadas duas semeaduras para a obtenção dos porta-enxertos. Na primeira (30-10-2001), utilizaram-se 100 sementes de cada porta-enxerto sem qualquer tratamento prévio. Na segunda (07-122001), foram utilizadas 120 sementes de cada portaenxerto, previamente embebidas em água destilada por cerca de doze horas e, posteriormente, semeadas em bandejas plásticas com substrato comercial Plantmax para hortaliças, composto por uma mistura de casca de Pinus, vermiculita e carvão ativado, na proporção de 3:1:1 (v:v). Da mesma forma, foram produzidos os "seedlings" de maracujazeiro-amarelo para fornecimento dos garfos, semeando-se a cada semana 100 sementes em uma bandeja, durante sete semanas. Quando os porta-enxertos e enxertos atingiram a fase de enxertia (janeiro de 2002), cerca de 6 a $8 \mathrm{~cm}$ de altura, e uma a duas folhas definitivas, o que ocorreu com cerca de 30 dias após a semeadura para as espécies mais precoces ou vigorosas, e 90 para as de crescimento mais lento, realizou-se a enxertia.

Os tratamentos utilizados foram seis portaenxertos: $P$. edulis f. flavicarpa, $P$. caerulea, $P$. alata, $P$. gibertii, $P$. coccinea, $P$. cincinnata e um tratamento pé-franco de $P$. edulis f. flavicarpa. Para todos os tratamentos, a variedade-copa utilizada foi o maracujazeiro-amarelo ‘FB 200'. Essa seleção foi obtida através da mistura de vários genótipos desen- 
volvidos na região de Araguari - MG, com objetivo de obter frutos para a indústria; entretanto, usa-se para o consumo in natura, pois tem como características frutos com maior uniformidade de tamanho, formato e cor (peso médio de $240 \mathrm{~g}$ ), casca mais grossa, proporcionando maior resistência durante o transporte, rendimento de suco em torno de $36 \%, 14,0^{\circ}$ Brix, produzindo $50 \mathrm{t} / \mathrm{ha} / \mathrm{ano}$.

O delineamento experimental utilizado foi o de blocos ao acaso, com três repetições. A parcela era constituída de uma linha de 20 metros de comprimento, contendo quatro plantas. O espaçamento utilizado foi de $3 \mathrm{~m}$ entre linhas e $5 \mathrm{~m}$ entre plantas. Previamente, foi feita a análise de solo da área a instalar-se ao pomar e, de acordo com o resultado da análise de solo (Tabela 1), verificou-se a necessidade de calagem e adubação.

Assim, a adubação baseou-se nas recomendações de adubação feitas por Van Raij (1997). Como o valor da saturação por bases (V), em Jaboticabal-SP, foi maior que $60 \%$, e o teor de magnésio foi maior que $9 \mathrm{mmol} / \mathrm{dm}^{3}$, não foi necessária a realização da calagem. $\mathrm{O}$ preparo do solo constituiu-se em uma aragem profunda, seguida de duas gradagens em sentido cruzado. A seguir, abriram-se sete sulcos de $60 \mathrm{~m}$ de comprimento e distanciados de $3 \mathrm{~m}$ entre si, no local onde seriam instaladas as espaldeiras. Nos sulcos, com auxílio de uma pipa, distribuíram-se 7.000 L de fluido de biodigestor. Posteriormente, piquetiaram-se as linhas, marcando o local das plantas e das estacas das espaldeiras, e usando-se uma broca acoplada ao trator, perfuraram-se covas de cerca de $0,5 \mathrm{~m}$ de profundidade para plantas e 1,2 $\mathrm{m}$ para estacas. Construíram-se, então, as espaldeiras com um fio de arame a $2 \mathrm{~m}$ de altura e realizou-se a adubação de fundação com $200 \mathrm{~g}$ de calcário dolomítico, 40 $\mathrm{g}$ de FTE BR-12 e 1,18 kg de superfosfato simples por cova.

Passados 30 dias, efetuou-se o plantio das mudas, em 02 de abril de 2002, seu tutoramento com uma pequena estaca de bambu e um fio de barbante, e o coroamento da cova. As mudas foram regadas duas vezes por semana até a época das chuvas. A adubação de formação foi realizada em cobertura, com $22 \mathrm{~g}$ de ureia, aos 30 dias, $33 \mathrm{~g}$ de ureia aos 60 dias, $112 \mathrm{~g}$ de ureia e $83 \mathrm{~g}$ de $\mathrm{KCl}$ aos 90 dias, por planta. A adubação de produção foi realizada também em cobertura, com $150 \mathrm{~g}$ de superfosfato simples, mais $40 \mathrm{~g}$ de FTE BR-12, em setembro/2002, 0,7 kg de NPK 20-5-20 divididos em 5 parcelas mensais/ planta, de setembro/2002 a janeiro/2003.

A adubação e a calagem, em AraguariMG, particularmente, obedeceram a outras formas de aplicação, de acordo com a recomendação. A calagem foi feita previamente, em área total, conforme análise de solo, visando a elevar a saturação por bases a V\% $=80$, utilizando calcário calcítico, PRNT 80. O preparo do solo constituiu-se em uma aração profunda $(25 \mathrm{~cm})$, seguida de uma gradagem. Foram feitas covas de 50x50x50 cm. A adubação de fundação foi de $20 \mathrm{~L}$ de esterco de curral curtido, $450 \mathrm{~g}$ de superfosfato simples e $50 \mathrm{~g}$ de FTE BR 12 por planta. A adubação de formação foi realizada em cobertura, com $250 \mathrm{~g}$ de $\left(\mathrm{NH}_{4}\right) 2 \mathrm{SO}_{4} \mathrm{e}$ $250 \mathrm{~g}$ de $\mathrm{KCl}$ por planta, parcelada em três aplicações espaçadas a cada 30 dias. O plantio foi realizado em 09-04-2002. A adubação de produção foi realizada em cobertura, com 1,6 kg de $\left(\mathrm{NH}_{4}\right) 2 \mathrm{SO}_{4}$ e 1,6 kg de $\mathrm{KCl}$, em parcelas iguais, aplicados quinzenalmente por cova, a partir do mês de agosto de 2002 até abril de 2003. Além disso, em 15 de setembro de 2002, foi feita uma adubação de reforço de produção, com 500 $\mathrm{g}$ de superfosfato simples, $10 \mathrm{~L}$ de esterco de curral curtido e $50 \mathrm{~g}$ de FTE BR 12 por planta.

As plantas foram conduzidas em hastes únicas até ultrapassarem o arame da espaldeira (2 $\mathrm{m}$ de altura) em cerca de $10 \mathrm{~cm}$, quando foram despontadas para induzir a emissão dos ramos secundários. Esses, por sua vez, foram despontados quando atingiram a planta vizinha para forçar a emissão de ramos terciários. As plantas eram pulverizadas preventiva e/ou curativamente a cada quinze dias, com oxicloreto de cobre, na proporção de $3 \mathrm{~g}$ do produto comercial por litro de água. Para o controle de pragas, sempre que necessário, aplicouse dimetoato, à proporção de $2 \mathrm{~mL}$ do produto comercial por litro.

Diariamente, à tarde, após o horário de abertura das flores, que acontece a partir das 14 horas, percorria-se o pomar recolhendo anteras de flores de várias plantas em um recipiente e em quantidade suficiente para a florada do dia, que se encerra no final do período matutino com o fechamento das flores. Essas abrem-se apenas uma vez, não se permitindo polinizar no dia seguinte. Posteriormente, enquanto as flores permaneciam abertas durante o período matutino, misturavam-se as anteras e voltava-se a percorrer todo o pomar, transferindo-se uma miscelânea de grãos de pólen de várias plantas para os estigmas de cada flor, fazendo-se o trabalho de distribuição de pólen flor a flor com uso de dedal, por todas as flores, processo similar ao executado pelas mamangavas,que são os insetos polinizadores naturais do maracujazeiro. Dessa forma, tentou-se evitar o efeito da autoincompatibilidade e incompatibilidade cruzada apresentadas pelo maracujazeiro-amarelo. Foram 
avaliados o florescimento pela contagem do número de flores, a produção, o número e o peso médio de frutos pela contagem e pesagem dos frutos.

\section{RESULTADOS E DISCUSSÃO}

As características peso médio semanal de frutos e número semanal de frutos mostraram comportamentos semelhantes; as duas apresentaram diferença significativa entre porta-enxertos apenas na $8^{\mathrm{a}}$ e $12^{\mathrm{a}}$ semanas, sendo que o número semanal de frutos também diferiu na 14a (Tabelas 2;3;4;6;7 e 8). Para essas duas características, o comportamento das espécies, ao longo do tempo, foi de primeiro apresentar uma tendência de crescimento até a $13^{a}$ semana e,a partir daí, passaram a decrescer, tendo sido registrado o pico de produção entre a $8^{a}$ e a $14^{a}$ semana. Já o peso médio semanal de frutos não apresentou diferença significativa nem entre espécies, nem entre as diversas avaliações realizadas, apesar de ter apresentado uma ligeira tendência decrescente a partir da $8^{a}$ semana. Esse fato pode ser explicado pelo aumento do número de frutos na planta, com o passar do tempo, e por isso, maior número de frutos a serem nutridos, como também, fisiologicamente, mais por competição entre os frutos do que pelo gradual esgotamento das reservas da planta, além do clima e seus efeitos na planta, refletindo-se na nutrição dos frutos.

A contagem do número de flores foi uma tentativa de estabelecer-se uma metodologia para estimar o potencial produtivo das plantas, uma vez que muitos fatores como: autoincompatibilidade, incompatibilidade cruzada, esterilidade, ausência ou número insuficiente de polinizadores, polinização artificial deficiente, lavagem do pólen por chuva antes que duas horas se completassem após a polinização, 0 estresse hídrico, deficiência nutricional, a ocorrência de pragas e doenças diretamente relacionadas a flores e frutos (STAVELEY;WOLSTENHOLME, 1990; BRUCKNER, 1994A; BRUCKNER, 1994B; BRUCKNER et al., 1995; RUGGIERO et al., 1998; NOGUEIRA FILHO;RUGGIERO, 1998; BRUCKNER et al., 2002; LIBERATO, 2002) influenciam no pegamento de frutos e na produção final. Considera-se que a maioria dos fatores acima citados foram relativamente controlados através da realização de polinização artificial eficiente com uma miscelânea de pólen, controle fitossanitário preventivo e/ou curativo sistemáticos, adubação adequada e rega periódica no período crítico de seca. Exceto dois fatores que não puderam ser controlados: a incidência de pancadas de chuva à tarde, logo após a polinização, em alguns dias, e a esterilidade, pois uma planta (enxertada sobre $P$. alata), das 84 , apresentou uma fêmea esterilidade severa. Assim, esperava-se que houvesse uma coincidência entre o número de flores e as variáveis: produção total e número total de frutos, o que não aconteceu completamente (Tabelas 5; 9 e 10). Esse fato pode ter ocorrido por influência dos fatores que não se podem controlar. Mas há também que se ponderar que os diferentes porta-enxertos apresentaram diferenças de precocidade e, mesmo entre plantas de um mesmo porta-enxerto, notou-se essa diferença de precocidade. Assim sendo, quando se escolheram os três períodos de dez dias para realizar-se a avaliação de florescimento, pode-se ter privilegiado um ou outro tratamento por estar apresentando ou não um pico de florescimento. Dessa forma, recomenda-se que, em experimentos futuros, essa avaliação seja ampliada para 60 dias ininterruptos, abrangendo o pico de produção do pomar. Vale ressaltar que essa é uma tarefa quase hercúlea, devido à grande mão de obra exigida, associando-se essa avaliação aos procedimentos normais de condução do pomar em alguns dias.

Entretanto, observando-se os resultados obtidos para o florescimento (Tabelas 5 e 9), nota-se a formação de um grupo bastante profícuo, formado por $P$. cincinnata, pé-franco, $P$. alata e $P$. edulis $\mathrm{f}$. flavicarpa sob $P$. edulis f. flavicarpa, em contraste com outro grupo de menor potencial produtivo, formado por $P$. alata, $P$. coccinea e $P$. caerulea sob $P$. edulis f. flavicarpa. Vale ressaltar que $P$. edulis $\mathrm{f}$. flavicarpa permaneceu num intermédio entre os dois grupos, tendo diferido significativamente apenas de P. caerulea.

As variáveis produção total e número total de frutos tiveram comportamento semelhante. $\mathrm{O}$ pé-franco apresentou igual desempenho em relação aos demais tratamentos, com maior valor para as duas características, embora não tenha diferido significativamente dos outros porta-enxertos. Já para peso médio do total de frutos, houve diferença significativa entre os tratamentos, e o $P$. cincinnata mostrou o melhor desempenho, tendo diferido significativamente apenas de P. alata (Tabela 10).

À luz dos resultados obtidos por estes outros autores (OLIVEIRA et al.,1983; SEIXAS et al., 1987; MALDONADO, 1991; STENZEL; CARVALHO, 1992), para características de produção, pode-se dizer que os resultados aqui são coincidentes e seguem na mesma direção. Ou seja, a planta enxertada é menos produtiva que a de pé-franco. Já em relação ao peso médio de frutos, observou-se a influência da espécie utilizada como porta-enxerto, o que diverge dos resultados encontrados na literatura e até mesmo dos resultados obtidos nos experimentos conduzidos em Jaboticabal-SP, e Araguari-MG. 
TABELA 1 - Resultados da análise química do solo da área experimental. Jaboticabal - SP, e Araguari - MG.

\begin{tabular}{lcccccccccc}
\hline \multirow{2}{*}{ Local } & $\begin{array}{c}\mathrm{pH} \mathrm{em} \\
\mathrm{CaCl}_{2}\end{array}$ & $\begin{array}{c}\text { M.O. } \\
\mathrm{g} / \mathrm{dm}^{3}\end{array}$ & $\begin{array}{c}\mathrm{P} \text { resina } \\
\mathrm{mg} / \mathrm{dm}^{3}\end{array}$ & $\mathrm{~K}$ & $\mathrm{Ca}$ & $\mathrm{Mg}$ & $\mathrm{H}+\mathrm{Al}$ & $\mathrm{SB}$ & $\mathrm{T}$ & $\mathrm{V}$ \\
\hline Jaboticabal-SP & 5,4 & 33 & 47 & 4,1 & 49 & 28 & 34 & 81,1 & 115,1 & 70 \\
Araguari-MG & 4,6 & 42 & 53 & 1,8 & 12 & 12 & 72 & 43,8 & 115,5 & 38 \\
\hline
\end{tabular}

TABELA 2 - Produção semanal de frutos, em quilogramas (kg.semana'11), das plantas de maracujazeiroamarelo produzidas por enxertia hipocotiledonar em plântulas de seis espécies de passifloras silvestres, em pomar experimental, em Jaboticabal - SP.

\begin{tabular}{|c|c|c|c|c|c|c|c|c|}
\hline \multirow{2}{*}{ Semana } & \multicolumn{7}{|c|}{ Espécies } & \multirow[b]{2}{*}{ Média } \\
\hline & Pé-franco & P. cincinnata & $\begin{array}{l}\text { P. edulis } \mathrm{f} . \\
\text { flavicarpa }\end{array}$ & P. gibertii & P. coccinea & P. alata & P. caerulea & \\
\hline 01 & $0,000 \mathrm{Ac}$ & $0,000 \mathrm{Ad}$ & 0,391 Ad & $0,000 \mathrm{Ae}$ & $0,000 \mathrm{Ac}$ & $0,000 \mathrm{Ac}$ & $0,000 \mathrm{Ab}$ & 0,056 \\
\hline 02 & $0,408 \mathrm{Ac}$ & $0,000 \mathrm{Ad}$ & 1,047 Acd & $0,064 \mathrm{Ae}$ & $0,094 \mathrm{Ac}$ & $0,000 \mathrm{Ac}$ & $0,077 \mathrm{Ab}$ & 0,345 \\
\hline 03 & $0,347 \mathrm{Ac}$ & $0,030 \mathrm{Ad}$ & $0,486 \mathrm{Ad}$ & $0,000 \mathrm{Ae}$ & $0,000 \mathrm{Ac}$ & $0,058 \mathrm{Ac}$ & $0,000 \mathrm{Ab}$ & 0,132 \\
\hline 04 & $0,135 \mathrm{Ac}$ & $0,000 \mathrm{Ad}$ & $0,246 \mathrm{Ad}$ & $0,000 \mathrm{Ae}$ & $0,000 \mathrm{Ac}$ & $0,000 \mathrm{Ac}$ & $0,000 \mathrm{Ab}$ & 0,054 \\
\hline 05 & $0,372 \mathrm{Ac}$ & $0,122 \mathrm{Ad}$ & $0,823 \mathrm{Ad}$ & $0,142 \mathrm{Ae}$ & $0,000 \mathrm{Ac}$ & $0,000 \mathrm{Ac}$ & $0,093 \mathrm{Ab}$ & 0,222 \\
\hline 06 & $0,424 \mathrm{Ac}$ & $0,415 \mathrm{Ad}$ & 1,131 Acd & $0,461 \mathrm{Ae}$ & $0,190 \mathrm{Ac}$ & $0,048 \mathrm{Ac}$ & $0,198 \mathrm{Ab}$ & 0.410 \\
\hline 07 & $1,756 \mathrm{Abc}$ & 2,427 Acd & 2,235 Acd & 1,312 Ade & $0,131 \mathrm{Ac}$ & $0,577 \mathrm{Abc}$ & $0,000 \mathrm{Ab}$ & 1,206 \\
\hline 08 & 9,984 Aab & 7,134 ABabc & 4,765 ABbcd & 7,729 ABabcd & 4,276 ABbc & 2,743 ABabc & $1,148 \mathrm{Bb}$ & 5,397 \\
\hline 09 & $11,552 \mathrm{Aa}$ & 9,425 Aab & $11,240 \mathrm{Aa}$ & 8,112 Aabc & 6,498 Aabc & 3,736 Aabc & $1,953 \mathrm{Ab}$ & 7,502 \\
\hline 10 & $12,588 \mathrm{Aa}$ & $10,057 \mathrm{Aa}$ & 9,742 Aab & 7,893 Aabcd & 6,237 Aabc & 3,857 Aabc & 2,655 Aab & 7,576 \\
\hline 11 & 6530 Aabc & $10,335 \mathrm{Aa}$ & $9,250 \mathrm{Aab}$ & $10,010 \mathrm{Aa}$ & 7,687 Aab & 4,620 Aabc & $2,877 \mathrm{abA}$ & 7,330 \\
\hline 12 & $12,700 \mathrm{Aa}$ & $9,183 \mathrm{ABab}$ & 5,315 ABabcd & 9,432 ABab & 7,452 ABab & 7,292 ABab & $3,750 \mathrm{abB}$ & 7.875 \\
\hline 13 & $14,438 \mathrm{Aa}$ & $11,516 \mathrm{Aa}$ & $10,845 \mathrm{Aa}$ & 8,107 Aabc & $12,347 \mathrm{Aa}$ & $9,765 \mathrm{Aa}$ & 6,942 Aa & 10,566 \\
\hline 14 & $11,142 \mathrm{Aa}$ & 8,157 Aabc & $10,827 \mathrm{Aa}$ & 4,882 Aabcde & $4,602 \mathrm{Abc}$ & 5,528 Aabc & 3,000 Aab & 6,877 \\
\hline 15 & 6,177Aabc & 5,678 Aabcd & 5,932 Aabcd & 2,845 Abcde & $3,068 \mathrm{Abc}$ & 3,157 Aabc & 3,247 Aab & 4,301 \\
\hline 16 & $2,010 \mathrm{Abc}$ & 2,530 Acd & 2,382 Acd & 1,610 Acde & 0,973 Abc & 3,070 Aabc & 2,383 Aab & 2,137 \\
\hline 17 & 1,932 Abc & 3,602 Acd & 4,530 Abcd & 3,162 Abcde & $1,472 \mathrm{Abc}$ & 1,693 Abc & $1,318 \mathrm{Ab}$ & 2,530 \\
\hline Total & 92,495 & 80,611 & 81,187 & 65,761 & 55,027 & 46,144 & 29,641 & \\
\hline
\end{tabular}

- Médias seguidas de mesma letra, maiúscula na horizontal e minúscula na vertical, não diferem significativamente, pelo teste de Tukey, a $5 \%$.Dados obtidos para uma parcela de quatro plantas, em espaçamento $3 \times 5 \mathrm{~m}$. 
TABELA 3 - Número semanal de frutos das plantas de maracujazeiro-amarelo produzidas por enxertia hipocotiledonar em plântulas de seis espécies de passifloras silvestres, em pomar experimental, em Jaboticabal-SP.

\begin{tabular}{ccccccccc}
\hline \multirow{2}{*}{ Semana } & \multicolumn{7}{c}{ Espécies } & \\
\cline { 2 - 7 } & Pé-franco & P. cincinnata & $\begin{array}{c}\text { P. edulis f. } \\
\text { flavicarpa }\end{array}$ & P. gibertii & P. coccínea & P. alata & P. caerulea & \\
\hline $\mathbf{0 1}$ & $0,00 \mathrm{Ae}$ & $0,00 \mathrm{Ac}$ & $1,33 \mathrm{Ae}$ & $0,00 \mathrm{Ae}$ & $0,00 \mathrm{Ac}$ & $0,00 \mathrm{Ac}$ & $0,00 \mathrm{Ab}$ & 0,19 \\
$\mathbf{0 2}$ & $3,00 \mathrm{Ae}$ & $4,67 \mathrm{Ac}$ & $7,33 \mathrm{Ade}$ & $0,33 \mathrm{Ae}$ & $0,33 \mathrm{Ac}$ & $0,00 \mathrm{Ac}$ & $0,33 \mathrm{Ab}$ & 2,29 \\
$\mathbf{0 3}$ & $2,00 \mathrm{Ae}$ & $0,33 \mathrm{Ac}$ & $3,00 \mathrm{Ae}$ & $0,00 \mathrm{Ae}$ & $0,00 \mathrm{Ac}$ & $0,33 \mathrm{Ac}$ & $0,00 \mathrm{Ab}$ & 0,81 \\
$\mathbf{0 4}$ & $1,00 \mathrm{Ae}$ & $0,00 \mathrm{Ac}$ & $1,67 \mathrm{Ae}$ & $0,00 \mathrm{Ae}$ & $0,00 \mathrm{Ac}$ & $0,00 \mathrm{Ac}$ & $0,00 \mathrm{Ab}$ & 0,38 \\
$\mathbf{0 5}$ & $2,00 \mathrm{Ae}$ & $1,00 \mathrm{Ac}$ & $4,33 \mathrm{Ae}$ & $1,00 \mathrm{Ae}$ & $1,00 \mathrm{Ac}$ & $0,00 \mathrm{Ac}$ & $0,67 \mathrm{Ab}$ & 1,29 \\
$\mathbf{0 6}$ & $2,33 \mathrm{Ae}$ & $2,00 \mathrm{Ac}$ & $6,33 \mathrm{Ade}$ & $2,67 \mathrm{Ae}$ & $1,33 \mathrm{Ac}$ & $0,33 \mathrm{Ac}$ & $1,00 \mathrm{Ab}$ & 2,29 \\
$\mathbf{0 7}$ & $10,67 \mathrm{Ade}$ & $13,67 \mathrm{Abc}$ & $12,67 \mathrm{Ade}$ & $7,33 \mathrm{Ade}$ & $0,67 \mathrm{Ac}$ & $5,00 \mathrm{Abc}$ & $0,00 \mathrm{Ab}$ & 7,14 \\
$\mathbf{0 8}$ & $61,33 \mathrm{Aabcd}$ & $40,67 \mathrm{ABabc}$ & $27,33 \mathrm{ABbcde}$ & $45,33 \mathrm{ABabcd}$ & $21,67 \mathrm{ABbc}$ & $17,67 \mathrm{ABbc}$ & $6,33 \mathrm{Bb}$ & 31,48 \\
$\mathbf{0 9}$ & $73,67 \mathrm{Aabc}$ & $55,00 \mathrm{Aab}$ & $65,00 \mathrm{Aa}$ & $46,00 \mathrm{Aabcd}$ & $38,00 \mathrm{Abc}$ & $21,67 \mathrm{Abc}$ & $11,67 \mathrm{Ab}$ & 44,43 \\
$\mathbf{1 0}$ & $79,00 \mathrm{Aabc}$ & $55,33 \mathrm{Aab}$ & $61,33 \mathrm{Aab}$ & $44,67 \mathrm{Aabcd}$ & $34,33 \mathrm{Abc}$ & $22,00 \mathrm{Abc}$ & $17,67 \mathrm{Ab}$ & 44,91 \\
$\mathbf{1 1}$ & $38,00 \mathrm{Acde}$ & $64,33 \mathrm{Aa}$ & $62,33 \mathrm{Aab}$ & $67,33 \mathrm{Aa}$ & $51,67 \mathrm{Aabc}$ & $29,67 \mathrm{Aabc}$ & $19,00 \mathrm{Ab}$ & 47,48 \\
$\mathbf{1 2}$ & $94,67 \mathrm{Aab}$ & $65,67 \mathrm{ABa}$ & $36,33 \mathrm{Babcde}$ & $63,67 \mathrm{ABab}$ & $59,67 \mathrm{ABab}$ & $44,33 \mathrm{ABab}$ & $24,33 \mathrm{Bab}$ & 55,52 \\
$\mathbf{1 3}$ & $101,67 \mathrm{Aa}$ & $75,00 \mathrm{Aa}$ & $64,67 \mathrm{Aa}$ & $58,00 \mathrm{Aabc}$ & $92,00 \mathrm{Aa}$ & $65,33 \mathrm{Aa}$ & $55,00 \mathrm{Aa}$ & 73,10 \\
$\mathbf{1 4}$ & $81,67 \mathrm{Aabc}$ & $51,67 \mathrm{ABab}$ & $64,67 \mathrm{ABa}$ & $33,67 \mathrm{ABabcde}$ & $33,33 \mathrm{ABbc}$ & $38,33 \mathrm{ABabc}$ & $19,67 \mathrm{Bab}$ & 46,57 \\
$\mathbf{1 5}$ & $42,00 \mathrm{Abcde}$ & $39,00 \mathrm{Aabc}$ & $35,00 \mathrm{Aabcde}$ & $21,00 \mathrm{Acde}$ & $22,33 \mathrm{Abc}$ & $19,67 \mathrm{Abc}$ & $21,33 \mathrm{Aab}$ & 28,62 \\
$\mathbf{1 6}$ & $15,33 \mathrm{Ade}$ & $17,33 \mathrm{Abc}$ & $18,33 \mathrm{Acde}$ & $12,67 \mathrm{Ade}$ & $8,33 \mathrm{Abc}$ & $19,67 \mathrm{Abc}$ & $16,00 \mathrm{Ab}$ & 15,38 \\
$\mathbf{1 7}$ & $15,33 \mathrm{Ade}$ & $21,33 \mathrm{Abc}$ & $28,67 \mathrm{Abcde}$ & $23,00 \mathrm{Abcde}$ & $10,67 \mathrm{Abc}$ & $14,00 \mathrm{Abc}$ & $10,00 \mathrm{Ab}$ & 17,57 \\
\hline Média & 36,68647 & 29,82353 & 29,43059 & 25,09824 & 22,07824 & 17,52941 & 11,94118 & 24,67353 \\
\hline
\end{tabular}

Médias seguidas de mesma letra, maiúscula na horizontal e minúscula na vertical, não diferem significativamente, pelo teste de Tukey, a $5 \%$. Dados obtidos para uma parcela de quatro plantas, em espaçamento $3 \times 5 \mathrm{~m}$.

TABELA 4 - Peso médio semanal de frutos, em quilogramas (kg), das plantas de maracujazeiro-amarelo produzidas por enxertia hipocotiledonar em plântulas de seis espécies de passifloras silvestres, em pomar experimental, no período, em Jaboticabal - SP.

\begin{tabular}{|c|c|c|c|c|c|c|c|c|}
\hline \multirow[b]{2}{*}{ Semana } & \multicolumn{7}{|c|}{ Espécies } & \multirow[b]{2}{*}{ Média } \\
\hline & $\begin{array}{c}\text { P. edulis } \\
\text { f. flavicarpa }\end{array}$ & P. caerulea & P. alata & P. coccinea & P. gibertii & P. cincinnata & Pé-franco & \\
\hline 01 & 0,294 & & & & & & |---------- & $0,2935 \mathrm{~A}$ \\
\hline 02 & 0,138 & 0,230 & & 0,283 & 0,191 & 0,121 & 0,140 & $0,1604 \mathrm{~B}$ \\
\hline 03 & 0,170 & & 0,175 & ------ & ------------ & 0,089 & 0,173 & $0,1553 \mathrm{~B}$ \\
\hline 04 & 0,144 & & & & & & 0,158 & $0,1508 \mathrm{~B}$ \\
\hline 05 & 0,186 & 0,140 & & ----------- & 0,144 & 0,109 & 0,187 & $0,1579 \mathrm{~B}$ \\
\hline 06 & 0,154 & 0,198 & 0,144 & 0,143 & 0,172 & 0,157 & 0,168 & $0,1615 \mathrm{~B}$ \\
\hline 07 & 0,161 & ------------- & 0,189 & 0,197 & 0,180 & 0,197 & 0,154 & $0,1767 \mathrm{~B}$ \\
\hline 08 & 0,177 & 0,196 & 0,160 & 0,197 & 0,167 & 0,185 & 0,164 & $0,1781 \mathrm{~B}$ \\
\hline 09 & 0,174 & 0,171 & 0,182 & 0,182 & 0,174 & 0,172 & 0,157 & $0,1733 \mathrm{~B}$ \\
\hline 10 & 0,164 & 0,184 & 0,188 & 0,194 & 0,180 & 0,181 & 0,155 & $0,1779 \mathrm{~B}$ \\
\hline 11 & 0,163 & 0,157 & 0,159 & 0,150 & 0,147 & 0,164 & 0,179 & $0,1598 \mathrm{~B}$ \\
\hline 12 & 0,153 & 0,157 & 0,155 & 0,127 & 0,149 & 0,144 & 0,134 & $0,1455 \mathrm{~B}$ \\
\hline 13 & 0,168 & 0,137 & 0,150 & 0,139 & 0,138 & 0,154 & 0,144 & $0,1470 \mathrm{~B}$ \\
\hline 14 & 0,154 & 0,147 & 0,145 & 0,139 & 0,150 & 0,158 & 0,133 & $0,1465 \mathrm{~B}$ \\
\hline 15 & 0,158 & 0,153 & 0,160 & 0,143 & 0,148 & 0,150 & 0,149 & $0,1517 \mathrm{~B}$ \\
\hline 16 & 0,125 & 0,146 & 0,150 & 0,125 & 0,145 & 0,150 & 0,130 & $0,1386 \mathrm{~B}$ \\
\hline 17 & 0,157 & 0,129 & 0,123 & 0,132 & 0,132 & 0,163 & 0,129 & $0,1379 \mathrm{~B}$ \\
\hline Média & 0,1670588 & 0,165 & 0,16 & 0,165462 & 0,158357 & 0,152933 & 0,153375 & 0,165435 \\
\hline
\end{tabular}

Médias seguidas de mesma letra, maiúscula na vertical, não diferem significativamente, pelo teste de Tukey, a $5 \%$.Dados obtidos para uma parcela de quatro plantas, em espaçamento $3 \times 5 \mathrm{~m}$. 
TABELA 5 - Florescimento das plantas de maracujazeiro-amarelo produzidas por enxertia hipocotiledonar em plântulas de seis espécies de passifloras silvestres, em pomar experimental, em Jaboticabal - SP.

\begin{tabular}{lc}
\hline Espécies & Número de flores para 5 m lineares \\
\hline$P$. cincinnata & $10,26 \mathrm{~A}^{1,2}$ \\
$P$. edulis f. flavicarpa (pé-franco) & $10,48 \mathrm{~A}$ \\
P. alata & $10,78 \mathrm{~A}$ \\
P. edulis f. flavicarpa & $8,21 \mathrm{AB}$ \\
P. gibertii & $6,06 \mathrm{BC}$ \\
$P$. coccinea & $6,34 \mathrm{BC}$ \\
$P$. caerulea & $4,73 \mathrm{C}$ \\
\hline & $12,24 * *$ \\
"F” para porta-enxerto Coeficiente de variação (\%) & 50,19 \\
\hline
\end{tabular}

${ }^{1}$ Dados não transformados.

${ }^{2}$ Médias seguidas de mesma letra não diferem significativamente pelo teste de Tukey, a 5\%..

TABELA 6 - Produção por colheita, em quilogramas $\left(\mathrm{kg} \cdot \mathrm{colheita}^{-1}\right)$, das plantas de maracujazeiro-amarelo produzidas por enxertia hipocotiledonar em plântulas de cinco espécies de passifloras silvestres, em pomar comercial, em Araguari - MG.

\begin{tabular}{|c|c|c|c|c|c|c|c|}
\hline \multirow[b]{2}{*}{ Colheita } & \multicolumn{6}{|c|}{ Espécies } & \multirow[b]{2}{*}{ Média } \\
\hline & Pé-franco & $\begin{array}{l}\text { P. edulis } \mathrm{f} . \\
\text { flavicarpa }\end{array}$ & P. caerulea & P. gibertii & P. cincinnata & P. alata & \\
\hline 01 & 10,67 & 10,67 & 8,67 & 7,33 & 7,00 & $\overline{5,00}$ & 8,22 bc \\
\hline 02 & 11,67 & 9,33 & 7,33 & 6,33 & 5,33 & 5,00 & 7,50 \\
\hline 03 & 11,67 & 10,00 & 9,33 & 8,67 & 7,33 & 6,00 & $8,83 \mathrm{abc}$ \\
\hline 04 & 10,67 & 10,67 & 11,67 & 11,00 & 7,67 & 7.00 & $9,78 \mathrm{ab}$ \\
\hline 05 & 11,33 & 11,33 & 11,33 & 12,00 & 8,00 & 7,00 & $10,17 \mathrm{a}$ \\
\hline 06 & 9,00 & 8,67 & 9,00 & 8,33 & 6,67 & 4.33 & 7,67 \\
\hline 07 & 5,67 & 4,67 & 5,67 & 5,33 & 5,67 & 2,33 & 4,89 \\
\hline 08 & 4,00 & 3,00 & 5,00 & 3,67 & 4,33 & 2,00 & 3,67 \\
\hline Total & 74,68 & 68,34 & 68 & 62,66 & 52 & 27,33 & 60,73 \\
\hline
\end{tabular}

- Médias seguidas de mesma letra, não diferem significativamente, pelo teste de Tukey, a 5\%.

TABELA 7 - Número de frutos por colheita, das plantas de maracujazeiro-amarelo produzidas por enxertia hipocotiledonar em plântulas de cinco espécies de passifloras silvestres, em pomar comercial, em Araguari-MG.

\begin{tabular}{|c|c|c|c|c|c|c|c|}
\hline \multirow[b]{2}{*}{ Colheita } & \multicolumn{6}{|c|}{ Espécies } & \multirow[b]{2}{*}{ Média } \\
\hline & Pé-franco & P. caerulea & $\begin{array}{l}\text { P. edulis } \mathrm{f} . \\
\text { flavicarpa }\end{array}$ & P. gibertii & P. cincinnata & P. alata & \\
\hline 01 & 49,67 & 40,00 & 47,67 & 33,00 & 31,00 & 27,00 & $38,01 \mathrm{ab}$ \\
\hline 02 & 56,00 & 34,33 & 45,00 & 30,00 & 24,00 & 28,00 & $36,22 \mathrm{~b}$ \\
\hline 03 & 56,33 & 43,00 & 45,33 & 39,67 & 33,00 & 32,33 & $41,61 \mathrm{ab}$ \\
\hline 04 & 52,67 & 54,33 & 53,67 & 50,67 & 37,67 & 38,00 & 47,83 a \\
\hline 05 & 48,67 & 51,67 & 47,33 & 52,33 & 32,33 & 34,67 & $44,50 \mathrm{ab}$ \\
\hline 06 & 42,33 & 41,33 & 39,00 & 37,67 & 29,00 & 23,33 & $35,44 \mathrm{~b}$ \\
\hline 07 & 26,33 & 26,00 & 22,00 & 25,00 & 24,67 & 13,00 & $22,83 \mathrm{c}$ \\
\hline 08 & 18,67 & 23,00 & 13,33 & 17,00 & 19,00 & 11,33 & $17,06 \mathrm{c}$ \\
\hline Total & 350,67 & 313,66 & 313,33 & 285,34 & 230,67 & 207,66 & 283,5 \\
\hline DMS 11,61 & & & & & & & \\
\hline
\end{tabular}

Médias seguidas de mesma letra, não diferem significativamente, pelo teste de Tukey, a 5\%.

Dados obtidos para uma parcela de quatro plantas, em espaçamento $3 \times 5 \mathrm{~m}$ 
TABELA 8 - Peso médio de frutos por colheita, em quilogramas (kg.colheita-1 ${ }^{-1}$, das plantas de maracujazeiroamarelo produzidas por enxertia hipocotiledonar em plântulas de cinco espécies de passifloras silvestres, em pomar comercial, em Araguari - MG.

\begin{tabular}{|c|c|c|c|c|c|c|c|}
\hline \multirow[b]{2}{*}{ Colheita } & \multicolumn{6}{|c|}{ Espécies } & \multirow[b]{2}{*}{ Média } \\
\hline & P. gibertii & P. caerulea & P. cincinnata & $\begin{array}{l}\text { P. edulis } \mathrm{f} . \\
\text { flavicarpa }\end{array}$ & Pé-franco & P. alata & \\
\hline 01 & 0,223 & 0,217 & 0,237 & 0,227 & 0,217 & 0,177 & $0,216 \mathrm{ab}$ \\
\hline 02 & 0,212 & 0,220 & 0,229 & 0,219 & 0,212 & 0,168 & $0,214 \mathrm{ab}$ \\
\hline 03 & 0,220 & 0,221 & 0,228 & 0,225 & 0,209 & 0,173 & $0,217 \mathrm{ab}$ \\
\hline 04 & 0,217 & 0,214 & 0,221 & 0,205 & 0,204 & 0,179 & $0,207 \mathrm{~b}$ \\
\hline 05 & 0,191 & 0,225 & 0,322 & 0,244 & 0,233 & 0,191 & $0,234 \mathrm{a}$ \\
\hline 06 & 0,223 & 0,218 & 0,234 & 0,222 & 0,216 & 0,177 & $0,219 \mathrm{ab}$ \\
\hline 07 & 0,215 & 0,220 & 0,230 & 0,215 & 0,215 & 0,174 & $0,211 \mathrm{ab}$ \\
\hline 08 & 0,227 & 0,229 & 0,231 & 0,236 & 0,213 & 0,163 & $0,221 \mathrm{ab}$ \\
\hline Média & 0,223 & 0,217 & 0,237 & 0,227 & 0,217 & 0,177 & $0,216 \mathrm{ab}$ \\
\hline
\end{tabular}

Médias seguidas de mesma letra, não diferem significativamente, pelo teste de Tukey, a 5\%. Dados obtidos para uma parcela de quatro plantas, em espaçamento $3 \times 5 \mathrm{~m}$.

TABELA 9 - Florescimento das plantas de maracujazeiro-amarelo produzidas por enxertia hipocotiledonar em plântulas de cinco espécies de passifloras silvestres, em pomar comercial, em Araguari - MG.

\begin{tabular}{lc}
\hline Espécies & Número de flores para 5 m lineares \\
\hline P. edulis f. flavicarpa & $17,73 \mathrm{a}^{1,2}$ \\
P. caerulea & $13,09 \mathrm{ab}$ \\
P. gibertii & $11,91 \mathrm{ab}$ \\
P. edulis f. flavicarpa (pé-franco) & $11,39 \mathrm{~b}$ \\
P. cincinnata & $7,72 \mathrm{c}$ \\
P. alata & $6,23 \mathrm{~d}$ \\
\hline "F" para porta-enxerto & $25,91 * *$ \\
Coeficiente de variação (\%) & 59,60 \\
\hline
\end{tabular}

${ }^{1}$ Dados não transformados.

${ }^{2}$ Médias seguidas de mesma letra não diferem significativamente, pelo teste de Tukey, a $5 \%$.

TABELA 10 - Produção total (PT), número total de frutos (NTF), peso médio do total de frutos (PMTF), em quilogramas (kg.colheita ${ }^{-1}$ ), das plantas de maracujazeiro-amarelo produzidas por enxertia hipocotiledonar em plântulas de cinco espécies de passifloras silvestres, em pomar comercial, em Araguari - MG.

\begin{tabular}{|c|c|c|c|}
\hline \multirow{2}{*}{ Espécies } & \multicolumn{3}{|c|}{ Características de Produção } \\
\hline & PT & NTF & PMTF \\
\hline Pé-franco & $74,67 \mathrm{~A}^{1,2}$ & $350,67 \mathrm{~A}$ & $0,214 \mathrm{AB}$ \\
\hline P. edulis f. flavicarpa & $68,33 \mathrm{~A}$ & $313,33 \mathrm{~A}$ & $0,222 \mathrm{AB}$ \\
\hline P. caerulea & $68,00 \mathrm{~A}$ & $313,67 \mathrm{~A}$ & $0,218 \mathrm{AB}$ \\
\hline P. gibertii & $62,67 \mathrm{~A}$ & $285,33 \mathrm{~A}$ & $0,220 \mathrm{AB}$ \\
\hline P. cincinnata & $52,00 \mathrm{~A}$ & $230,67 \mathrm{~A}$ & $0,230 \mathrm{~A}$ \\
\hline P. alata & $38,67 \mathrm{~A}$ & $207,67 \mathrm{~A}$ & $0,175 \mathrm{~B}$ \\
\hline Média & 60,72 & 283,56 & 0,213 \\
\hline
\end{tabular}

${ }^{1}$ Médias seguidas de mesma letra não diferem significativamente, pelo teste de Tukey ,a $5 \%$.

${ }^{2}$ Dados obtidos para uma parcela de quatro plantas, em espaçamento 3 x $5 \mathrm{~m}$. 


\section{CONCLUSÕES}

1-A metodologia utilizada para avaliação de florescimento deve ser modificada em experimentos futuros, de forma a abranger todo o pico de florescimento de maneira ininterrupta.

2-As espécies Passiflora edulis f. flavicarpa, $P$. alata e $P$. cincinatta determinam o aparecimento inicial das flores precocemente.

3-Embora as plantas de pé-franco tenham superado numericamente a produção das enxertadas, não diferem significativamente delas. dos frutos.

4-A espécie Passiflora alata diminui o peso

\section{REFERÊNCIAS}

BRUCKNER, C.H. Autoincompatibilidade em maracujazeiro. In: SÃO JOSÉ, AR. Maracujá: produção e mercado. Vitória da Conquista: DFZ/ UESB, 1994b. p. 6-18.

BRUCKNER, C.H. Autoincompatíbilidade no maracujá (Passiflora edulis Sims). 85f. Tese (Doutorado em Genética e Melhoramento) Universidade Federal de Viçosa, Viçosa, 1994a.

BRUCKNER, C. H.; CASALI, V. W. D.; MORAES, C F.; REGAZZI, A. J.; SILVA, E. A. M. Selfincompatibility in passion fruit (Passifiora edulis Sims). Acta Horticulturae, Wageningen, n. 370, p. 45-57, 1995.

BRUCKNER, C.H.; MELETTI, L.M.M.; OTON, W.C.; ZERBINI JÚNIOR, F.M. Maracujazeiro. In: BRUCNER, C.H. (Ed.). Melhoramento de fruteiras tropicais. Viçosa: Universidade Federal de Viçosa, 2002. p. 373-409.

CHAVES, R. da C.; JUNQUEIRA, N.T.V.; MANICA, I.; PEIXOTO, J.R.; PEREIRA, A.V.; FIALHO, J.F. Enxertia de maracujazeiro-azedo em estacas herbáceas enraizadas de espécies de passifloras nativas. Revista Brasileira de Fruticultura, Jaboticabal, v.26, n.1, p.120-3, 2004.
IBGE - Sistema IBGE de Recuperação Automática/ Instituto Brasileiro de Geografia e Estatística (SIDRA). Produção Agrícola Municipal. Maracujá. Brasília: Ministério do Planejamento, Orçamento e Gestão. Disponível em: http://www.sidra.ibge.gov. $\mathrm{br} / \mathrm{bda} /$ tabela/protabl.asp? $\mathrm{c}=1613 \& \mathrm{z}=\mathrm{p} \& \mathrm{o}=22 \& \mathrm{i}=\mathrm{P}$. Acesso em: 02 dez. 2009.

JUNQUEIRA, N.T.V.; LAGE, D.A. da C.; BRAGA, M.F.; PEIXOTO, J.R.; BORGES, T.A.; ANDRADE, S.R.M. de. Reação a doenças e produtividade de um clone de maracujazeiro-azedo propagado por estaquia e enxertia em estacas herbáceas de Passiflora silvestre. Revista Brasileira de Fruticultura, Jaboticabal, v.28, n.1, p.97-100, 2006.

KAVATI, R.; PEREIRA, V.P. Maracujá para exportação: aspectos técnicos da produção. Brasília: Embrapa-SPI, 1996. 64p.

LIBERATO, J.R. Controle das doenças causadas por fungos, bactérias e nematoides em maracujazeiro. In: ZAMBOLIM, L.; VALE, F.X.R.; MONTEIRO, A.J.A.; COSTA, H. Controle de doenças de plantas: fruteiras. Viçosa: Universidade Federal de Viçosa, 2002. v.2, p.699-825.

MALDONADO, J.F.M. Utilização de porta-enxertos do gênero Passiflora para o maracujazeiro-amarelo (Passiflora edulis Sims f. flavicarpa Deg.). Revista Brasileira de Fruticultura, Jaboticabal, v. 13, n. 2, p. 51-54, 1991.

NOGUEIRA FILHO, G.C.; RUGGIERO, C. Implicações da autoincompatibilidade na produção de mudas e no melhoramento do maracujazeiro (Passiflora edulis Sims. f. flavicarpa Deg.). Boa Vista. Embrapa Roraima, 1998. 18 p. (Série Documentos, 3).

OLIVEIRA, J.C. de; NAKAMURA, K.; RUGGIERO, C.; FERREIRA, F.R. Determinação de fonte de resistência em Passifloraceas quanto à morte prematura de plantas. In: CONGRESSO BRASILEIRO DE FRUTICULTURA, 8., 1986, Brasília. Anais... Brasília: Sociedade Brasileira de Fruticultura, 1986. p. 403-407. 
RUGGIERO, C.; SÃO JOSÉ, A. R.; VOLPE, C. A.; OLIVEIRA, J.C.; DURIGAN, J.F.; BAUMGARTNER, J.G.; SILVA JR.; cia; NAKAMURA, K.; FERREIRA, M.E.; SILVA, J.R. Situação da cultura do maracujazeiro na região central Brasileira. In: SIMPÓSIO BRASILEIRO SOBRE A CULTURA DO MARACUJAZEIRO, 5., 1998. Anais... Jaboticabal: FUNEP, 1998. p. 18-19.

SEIXAS, L.F.Z.; OLIVEIRA, J.C.; TIHOHOD, D.; RUGGIERO, C. Comportamento de Passiflora macrocarpa como porta-enxerto para Passiflora edulis Sims f. flavicarpa Deg., cultivado em local com histórico de morte prematura de plantas e nematoides do maracujazeiro. In: CONGRESSO BRASILEIRO DE FRUTICULTURA, 9., 1987, Campinas. Anais... Campinas: Sociedade Brasileira de Fruticultura, 1987. p. 597-601.

SILVA, F.M.; CORREA, L. de S.; BOLIANI, A.C.; SANTOS, P.C. dos.Enxertia de mesa de Passiflora edulis Sims f. flavicarpa Deg. sobre Passiflora alata Curtis, em ambiente de nebulização intermitente. Revista Brasileira de Fruticultura, Jaboticabal, v.27, n.1, p.98, 2005.
STENZEL. N. M. C.; CARVAlho, S. L. C. Comportamento do maracujazeiro-amarelo (Passiflora edulis Sims f. flavicarpa Deg.) enxertado sobre diferentes porta-enxertos. Revista Brasileira de Fruticultura, Jaboticabal, v.14, n.3, p. 183-186, 1992.

STAVELEY, G.W.; WOLSTENHOLME, B.N. Effects of water stress on growth and flowering of Passiflora edulis Sims grafted to P. caerulea L. Acta Horticulturae, Wageningen, n. 275, p. 551$558,1990$.

VAN RAIJ, B.; CANTARELLA, H.; QUAGGIO, J.A.; FURLANI, A.M.C. (Ed.). Recomendações de adubação e calagem para o Estado de São Paulo. Campinas-SP: Instituto Agronômico de Campinas, 1997. 285p. (Boletim Técnico, 100). 